ORIGINAL ARTICLE

\section{J Korean}

Neuropsychiatr Assoc

2020;59(4):319-324

Print ISSN 1015-4817

Online ISSN 2289-0963

www.jknpa.org
Received September 2, 2020

Revised October 8, 2020

Accepted October 14, 2020

Address for correspondence

Ji-Hoon Kim, MD, PhD

Department of Psychiatry,

Pusan National University

Yangsan Hospital,

20 Geumo-ro, Mulgeum-eup,

Yangsan 50612, Korea

Tel +82-55-360-2123

Fax +82-55-360-2153

E-mail pnuhcap@gmail.com

\section{소아청소년 양극성장애 환자에서 리튬 치료에 따른 소변 오스몰랄농도의 변화}

양산부산대학교병원 정신건강의학과

정지운 · 최범성 · 김대욱 · 유은라 · 허성영 · 김성곤 · 김지훈

\section{Changes in Urine Osmolal Concentration with Lithium Treatment in Children and Youth with Bipolar Disorder}

Ji-Woon Jeong, MD, Bum-Sung Choi, MD, PhD, Dae-Wook Kim, MD, Eun-Ra Yu, MD, Sung-Young Huh, MD, Sung-Gon Kim, MD, PhD, and Ji-Hoon Kim, MD, PhD

Department of Psychiatry, Pusan National University Yangsan Hospital, Yangsan, Korea

Objectives Bipolar disorder has a high rate of recurrence, which can cause problems such as declines in cognitive and social functions. Lithium is the primary medication for preventing recurrence, but the medication compliance is poor owing to side effects that include diarrhea, tremor, polyuria, polydipsia, diabetes insipidus, increased creatinine level, and weight gain. Polyuria and polydipsia also cause voluntary discontinuation of the medication. However, no domestic and international studies have evaluated the direct correlation between lithium therapy and polydipsia in pediatric patients. Therefore, we assessed this relationship by evaluating urine osmolality changes after lithium administration in pediatric patients.

Methods This study focused on patients admitted to the Department of Psychiatry, Pusan National University Yangsan Hospital. Patients had bipolar disorder types I or II and other specified bipolar disorders based on the DSM-5, criteria at discharge from December 1, 2018, to April 31, 2020. Urine osmolarity changes from admission to discharge in the patients who used lithium for the first time after admission were reviewed.

Results For 47 patients, the change in osmolality was statistically significant (mean, 203.32 \pm 280.68; $p<0.001$ ) and significantly higher in those aged $<14$ years than in those aged $\geq 14$ years $(p=0.038)$. Antipsychotic use and sex-related differences did not affect urine osmolality.

Conclusion The first-time users of lithium had significantly reduced urine osmolality at discharge. Considering the lithium effect on the kidneys, a prospective study to identify the relationship between lithium use and polydipsia is necessary.

J Korean Neuropsychiatr Assoc 2020;59(4):319-324

KEY WORDS Bipolar disorder · Lithium · Polydipsia · Polyuria · Urine osmolality · Kidney function test.

\section{서 론}

양극성장애의 평생유병률은 I형의 경우 $1.0 \%$, II형의 경우 $1.1 \%$, 그 이외의 양극성장애의 경우 $2.4 \%$ 로 전체적으로 약 $4.4 \%$ 정도이다. ${ }^{1)}$ 양극성장애의 경우 높은 유병률에도 불구 하고 단일 조증 삽화가 있었던 환자의 경우 $90 \%$ 이상에서, 이후에 다른 삽화를 보일 정도로 재발률이 높고 만성적인 경과를 가지는 것으로 알려져 있다.,3) 특히, 삽화가 반복될 수록 환자의 인지기능 및 사회적기능의 저하를 야기하게 되
며 세계적으로도 자살로 인한 사망률 증가 등의 문제를 일 으키는 등 질병으로 인한 사회적 부담이 많다. ${ }^{4,5}$

이러한 특성으로 인하여 양극성장애의 재발 방지는 중요 하며 이 중 리튬은 1949년 $\mathrm{Cade}^{6}$ 에 의해 소개된 이후로 양극 성장애의 장기 치료제로 사용되고 있으며, 임상적으로 longterm efficacy가 가장 많이 입증된 약제이다. 리튬은 조증 삽 화의 재발을 약 $38 \%$, 우울 삽화의 재발을 약 $28 \%$ 줄이며 자 살 위험도는 $50 \%$ 이상을 줄이는 것으로 알려져 있다. ${ }^{7}$

하지만 양극성장애 환자의 약 $57 \%$ 에서 약물 치료의 충실 
도가 떨어지는 것으로 보이며, 이와 같은 약물의 자의적 중 단은 재발 위험을 $10.1 \%$ 에서 $63.0 \%$ 로 증가시키는 것으로 나 타났다.99) 이 중 리튬의 자의적 중단 원인으로는 사회, 환경 적 요소와 부작용이 있으며, 리튬의 중단을 유발하는 부작용 으로는 설사, 진전, 다뇨/다음증/요붕증, 크레아티닌의 상승, 체중 증가 순서였다. ${ }^{8,10-12)}$

리튬의 부작용 중 다뇨, 다음증은 약물 순응도를 낮추며 약 물의 자의적 중단을 유발하는 대표적인 증상이며 리튬 장기 치료 환자의 50 73\%에서 경험을 하게 된다. ${ }^{13-15)}$ 다뇨, 다음 증상의 심각도는 리튬 치료의 기간과 관련이 있으며 치료 초 반에는 가역적이나, 시간이 지남에 따라 비가역적으로 변화 하는 것으로 보인다. ${ }^{14-22)}$ 다뇨, 다음 증상이 있는 환자의 $40 \%$ 이상에서 일상 활동과 직업 생활에 영향을 받는 것으로 나타 났으며, 환자들은 탈수, 전해질 불균형, 리튬 독성 등의 부작 용을 경험할 위험성에 노출이 되는 것으로 보인다. ${ }^{18,19)}$

기존의 다음증에 관한 연구들에서 소변 오스몰랄농도는 신뢰할 만한 표지자로 사용되었고, ${ }^{23-26)}$ 외국에서 진행된 리 튬과 다음증의 관계에 대한 연구에서는 소변 오스몰랄농도 를 이용하여 진행되었다. ${ }^{19,27)}$ 하지만 지금까지 소아청소년을 대상으로 한 리튬과 다음증의 직접적인 상관관계를 살펴본 실험적인 연구는 국내뿐만 아니라 해외 연구도 전무하다. 따 라서 우리는 소아청소년 환자를 대상으로 리튬 투약 이후 생 기는 소변 오스몰랄농도를 변화를 이용하여 리튬 복용과 다 음증의 관계를 살펴보고자 한다.

\section{방 법}

\section{대 상}

본 연구는 2018년 12월 1일 2020년 4월 31일까지 양산부 산대학교병원 정신건강의학과 보호 병동 입원 환자 중, 퇴원 시 진단이 DSM-5의 양극성장애 I형, II형 및 기타 양극성 장 애인 환자를 대상으로 하였다. 입원 당시 나이가 19세 미만 인 환자를 대상으로 하였으며, 남성 22명, 여성 25명이었다. 의무기록상 진단이 불확실한 경우, 기질적 원인에 의한 기분 장애, 분열정동장애 및 조현병은 제외하였다. 입원 기간이 3 주 이상이며, 입원 전 4 주 동안 리튬 복용을 하지 않은 환자 를 대상으로 하였다. 입원 시 시행한 신기능 검사상 blood urea nitrogen(6.6 23.6 mg/dL), creatinine(0.51 0.95 mg/dL), estimated glomerular filtration rate $\left(>60 \mathrm{~mL} / \mathrm{min} / 1.73 \mathrm{~m}^{2}\right)$ 셋 중 하나라도 비정상 수치인 경우에는 배제하였다. 또한 신장 질환에 대한 가족력이 있는 경우에도 배제하였다.

입원 기록에 대하여 정신건강의학과 의사가 진료 기록을 검토, 수집하였으며, 후향적 연구로 진행했다. 본 연구는 양
산부산대학교병원 임상시험심사위원회(Institutional $\mathrm{Re}^{-}$ view Board)의 심사를 받은 후 진행되었다(05-2019-190).

\section{방 법}

입원 후 리튬의 목표 용량은 체중 $30 \mathrm{~kg}$ 이상 $40 \mathrm{~kg}$ 미만인 경우 $600 \mathrm{mg}, 40 \mathrm{~kg}$ 이상 $50 \mathrm{~kg}$ 미만인 경우 $750 \mathrm{mg}, 50 \mathrm{~kg}$ 이상 $60 \mathrm{~kg}$ 미만인 경우 $900 \mathrm{mg}, 60 \mathrm{~kg}$ 이상 $70 \mathrm{~kg}$ 미만인 경우 $1050 \mathrm{mg}, 70 \mathrm{~kg}$ 이상인 경우에는 $1200 \mathrm{mg}$ 이었다. 시작 용량은 $30 \mathrm{~kg}$ 이상 $40 \mathrm{~kg}$ 미만인 경우 $150 \mathrm{mg}, 40 \mathrm{~kg}$ 이상인 경우 $300 \mathrm{mg}$ 이었다. $30 \mathrm{~kg}$ 이상 $70 \mathrm{~kg}$ 미만인 경우 2일마다 $150 \mathrm{mg}$ 씩 목표 용량까지 증량하였으며, $70 \mathrm{~kg}$ 이상의 경우 매일 $150 \mathrm{mg}$ 씩 증량하였다.

혈중 리튬 농도(lithium therapeutic drug monitoring, 이하 lithium TDM) 검사는 투약 시각으로부터 12시간 후에 시행 하였다(p3=오전 7시, hora somni=오전 9시). 리튬 동일 용량 에서 5일간 용량 유지 후 lithium TDM 시행을 원칙으로 하 였으며 1주일에 1 2회 시행하였다. 첫 lithium TDM 결과와 임상 증상에 따라 lithium TDM은 0.6 1.2을 목표로 리튬 용 량을 조절하였다.

소변 오스몰랄농도는 아침 첫 소변을 대상으로 검사하였 다. 소변 오스몰랄농도 검사는 입원 후 1 주일에 1 2회 시행 하였다.

\section{분 석}

본 연구의 자료 분석은 SPSS 26.0.0.0 프로그램(IBM Corp., Armonk, NY, USA)을 이용하였으며 자료 분석 시 모든 통 계치의 유의 확률은 $\mathrm{p}<0.05$ 로 설정하였다. 실험 집단의 일 반적 특성과 분포는 평균과 표준편차, 그리고 빈도와 백분율 로 파악하였다. Primary outcome인 입원, 퇴원 시의 소변 오 스몰랄농도의 변화를 보기 위하여 paired t-test를 실시하였 다. Secondary outcome 중 14세 미만, 14세 이상의 입원, 퇴 원시의 소변 오스몰랄농도의 변화 차이 검증을 위해 independent t-test를 실시하였다. 또한 항정신병제 복용군, 성별 에 따른 입원, 퇴원 시의 소변 오스몰랄농도의 변화 차이 검 증도 independent t-test를 통하여 수행하였다.

\section{결 과}

입원 당시 최저 연령은 8세, 최고 연령은 18 세였으며 평균 연령은 $14.17( \pm 1.97)$ 세였다. 이 중 14 세 미만의 환자가 18 명 (38.3\%), 14 18세의 환자가 29명(61.7\%)이었으며 평균 입원 기간은 55.15일 $( \pm 16.98)$ 이었다. 성별은 남자가 22명(46.8\%), 여자가 25 명 (53.2\%)이었으며, 입원 경로는 응급실이 27명 
(57.4\%), 외래가 20명(42.6\%)이었다(표 1). 14세 미만 환자의 퇴원 시 lithium 평균 용량은 1041.67( \pm 207.22$) \mathrm{mg}, 14$ 세 이 상 환자의 퇴원 시 lithium 평균 용량은 1236.21 $( \pm 274.56) \mathrm{mg}$ 이었다. 14세 미만 환자의 퇴원 시 lithium TDM 평균은 0.927 $( \pm 0.148) \mathrm{mmol} / \mathrm{L}, 14$ 세 이상 환자의 퇴원 시 lithium TDM 평균은 0.891 $( \pm 0.154) \mathrm{mmol} / \mathrm{L}$ 이었다(표 1).

Primary outcome으로 전체 환자(47명)에서 입원 후 시행 한 첫 소변 오스몰랄농도와 퇴원 전 시행한 마지막 소변 오스 몰랄농도의 차이(입원 시 소변 오스몰랄농도-퇴원 시 소변 오스몰랄농도)는 평균 203.32( \pm 280.68$) \mathrm{mosm} / \mathrm{kg}$ 으로 유의 미한 변화가 있었다 $(\mathrm{p}<0.001)$ (표 2). 즉, 리튬 복용 이후 퇴원

Table 1. Demographic and clinical characteristics

\begin{tabular}{lc}
\hline \multicolumn{1}{c}{ Item } & Value \\
\hline Age, year & $14.17( \pm 1.97)$ \\
$<14$ years & $18(38.3)$ \\
$\geq 14$ years & $29(61.7)$ \\
Sex, female & $25(53.2)$ \\
Height, $\mathrm{cm}$ & $162.59( \pm 11.73)$ \\
Weight, kg & $57.80( \pm 14.59)$ \\
BMl, kg/m ${ }^{2}$ & $21.61( \pm 3.94)$ \\
Hospitalization period, day & $55.15( \pm 16.98)$ \\
Admission TDM, mmol/L & $0.52( \pm 0.20)$ \\
Discharge TDM, mmol/L & $0.91( \pm 0.15)$ \\
Discharge Lithium dose, mg & $1161.70( \pm 266.26)$ \\
Admission route & $27(57.4)$ \\
Emergency room & $20(42.6)$ \\
Out-patient department & \\
Dose of Lithium at discharge, mg & $1041.67( \pm 207.22)$ \\
$<14$ years & $1236.21( \pm 274.56)$ \\
$\geq 14$ years &
\end{tabular}

시의 소변 오스몰랄농도가 입원 시의 소변 오스몰랄농도에 비해 통계학적으로 유의하게 감소되었다.

Secondary outcome으로 환자(47명)를 나이 기준으로 14세 미만, 14 세 이상 군으로 나누어 입원 시와 퇴원 시의 소변 오 스몰랄농도 차이를 비교하였을 때, 14세 미만, 14세 이상 두 군 모두에서 소변 오스몰랄농도의 변화가 유의미하게 나타 났다( $\mathrm{p}<0.001, \mathrm{p}=0.015)$ (표 1). 14세 미만군과 14세 이상군을 비교하였을 때, 두 군 간에 입원 시 소변 오스몰랄농도는 통 계학적으로 유의미한 차이가 없었으나, 퇴원 시의 소변 오스 몰랄농도는 14 세 미만군이 14세 이상군에 비하여 낮은 경향 을 보였고( $\mathrm{p}=0.100), 14$ 세 미만군이 14 세 이상군에 비해 입 퇴원 시의 소변 오스몰랄농도의 변화가 유의미하게 컸다( $\mathrm{p}=$ 0.038)(표 3).

전체 환자(47명)에서 항정신병제 사용 여부에 따른 입원퇴원 시의 소변 오스몰랄농도 차이는 통계학적으로 유의하 지 않았다 $(\mathrm{p}=0.670)$. 성별에 따른 입원-퇴원 시의 소변 오스 몰랄농도 차이는 통계학적으로 유의하지 않았다 $(\mathrm{p}=0.434)$ (표 4). 즉, 항정신병제 사용 여부, 성별의 차이는 입원-퇴원 시의 소변 오스몰랄농도의 변화에 영향을 주지 않았다.

\section{고 찰}

현재까지 리튬을 장기간 복용한 성인 환자에서 신장기능 요붕증(nephrogenic diabetes insipidus), 만성콩팥병(chronic kidney disease)의 발생이 증가된다는 연구는 많으나 입원 환자를 대상으로 입원 기간 내에 나타나는 신장기능의 변화 를 알아본 연구는 없었다. ${ }^{12,28,29)}$ 특히, 앞서 지적한 것처럼 소 아청소년을 대상으로 리튬과 다음증의 상관관계를 살펴본 실험적인 연구는 국내, 국외를 비롯하여 전무하다. 본 연구 는 소아청소년 양극성장애 환자에서 리튬 투약 이후 생기는 소변 오스몰랄농도의 변화를 측정하여 리튬 투약과 다음증

Table 2. Urine osmolality at admission and discharge

\begin{tabular}{lcccc}
\hline & $\begin{array}{c}\text { Admission urine osmolality } \\
(\mathrm{mosm} / \mathrm{kg})\end{array}$ & $\begin{array}{c}\text { Discharge urine osmolality } \\
(\mathrm{mosm} / \mathrm{kg})\end{array}$ & $\begin{array}{c}\text { Difference urine osmolality } \\
(\mathrm{mosm} / \mathrm{kg})\end{array}$ & $\mathrm{p}$-value \\
\hline Total $(\mathrm{n}=47)$ & 664.15 & 460.83 & 203.32 & $<0.001^{*}$ \\
$<14$ years $(\mathrm{n}=18)$ & 699.83 & 389.61 & 310.22 & $<0.001^{*}$ \\
$\geq 14$ years $(\mathrm{n}=29)$ & 642.00 & 505.03 & 136.96 & 0.015 \\
\hline
\end{tabular}

*Paired t-test

Table 3. Differences in urine osmolal concentration by age

\begin{tabular}{lccc}
\hline & $<14$ years $(\mathrm{n}=18)$ & $\geq 14$ years $(\mathrm{n}=29)$ & $\mathrm{p}$-value \\
\hline Urine osmolality (admission) & 699.83 & 642.00 & 0.440 \\
Urine osmolality (discharge) & 389.61 & 505.03 & 0.100 \\
Urine osmolality (admission)-urine osmolality (discharge) & 310.22 & 136.97 & $0.038^{*}$ \\
\hline
\end{tabular}

*Independent t-test 
Table 4. Variation of urinary osmolal concentration by various factors

\begin{tabular}{lcccc}
\hline \multicolumn{1}{c}{ Urine osmolality } & Admission $(\mathrm{mosm} / \mathrm{kg})$ & Discharge $(\mathrm{mosm} / \mathrm{kg})$ & Difference $(\mathrm{mosm} / \mathrm{kg})$ & $\mathrm{p}$-value \\
\hline Antipsychotics & & & & 0.670 \\
Taking group $(\mathrm{n}=38)$ & 673.71 & 461.76 & 211.95 & 166.89 \\
$\quad$ group not taken $(\mathrm{n}=9)$ & 623.78 & 456.89 & & 0.434 \\
Sex & & & & 168.73 \\
Male $(\mathrm{n}=22)$ & 688.04 & 519.32 & 233.76 & \\
Female $(\mathrm{n}=25)$ & 643.12 & 409.36 & & \\
\hline
\end{tabular}

의 관계를 살펴보고자 한 첫 연구이다.

본 연구의 결과를 요약하여 보면 첫째, 입원 시 처음 측정 한 소변 오스몰랄농도에 비하여 퇴원 시에 측정한 소변 오스 몰랄농도는 통계학적으로 유의한 감소를 보였다. 이는 Rej 등 ${ }^{19)}$ 의 기존 연구들의 결과와 비슷한 소견을 보였다. 하지만 타 연구들에서는 성인과 노인에서의 차이를 살펴보았거나 리튬의 평균 사용 기간이 10.8년 정도로 리튬의 장기 효과에 대한 연구가 많았다. 현재까지 리튬 사용 시 요농축능의 저하 가 나타나는 시점에 대해서는 알려진 바가 많지 않으나 성인 의 경우, 소변 오스몰랄농도의 감소는 리튬 복용 시작 약 8주 이후부터 나타난다는 연구가 있다. ${ }^{30)}$ 결과를 일반화하기는 어려우나 본 연구에서는 평균 입원 기간이 $55.15( \pm 16.98)$ 일 로 리튬 사용 기간이 상대적으로 짧아 소아청소년에서 리튬 복용에 따른 소변 오스몰랄농도의 변화가 성인에 비해 더욱 빠른 시점에 나타난다고 해석할 수 있다. 현재까지 알려진 바 에 의하면 소아청소년에서 신기능에 영향을 주는 요소로는 성장에 따른 신장의 발달과 성숙, 기저 신장 질환, 약물, 그리 고 환경 및 유전적 요소 등이 알려져 있다. ${ }^{31-34)}$ 이번 연구 결 과에서 나타난 바와 같이, 소아청소년이 성인에 비하여 빠른 시점에 리튬이 신장기능에 영향을 미치는 것에 대한 생물학 적 기전 및 요인이 있는지에 대한 추가적인 연구가 필요할 것으로 보인다.

둘째, 14 세 미만군이 14 세 이상군에 비하여 입원 시 소변 오스몰랄농도에서 퇴원 시 소변 오스몰랄농도를 뺀 소변 오 스몰랄농도 변화량이 컸다. Very early onset bipolar disorder 에 대한 정의에 대해서는 정해진 합의가 없으며, 13세 미만, 14 세 미만, 15 세 미만으로 다양하게 정의가 되고 있다. ${ }^{35-37)}$ 이 연구에서는 14 세를 기준으로 14 세 미만군과 14 세 이상군 으로 나누어 소변 오스몰랄농도를 비교하였다. 연구 결과에 따르면 14세 미만군이 14세 이상군보다 퇴원 시 오스몰랄농 도가 더 낮은 경향성을 보였다 $(\mathrm{p}=0.10)$. 리튬이 다음증을 유 발하는 기전은 상대적으로 짧은 가역적 반응과 장기간 변화 를 일으키는 비가역적 반응으로 나눌 수 있다. 상대적으로 짧 은 가역적 반응은 신장의 집합세관에서 항이뇨호르몬(antidiuretic hormone) 자극에 반응하여 cyclic adenosine mo- nophosphate가 활성화, adenosine triphosphatases를 억제, aquaporin 합성을 저해를 유발하는 것으로 일어나며, 장기적 인 반응은 신장기능요붕증을 유발하여 다음증을 유발하게 된다. 현재까지 리튬이 신장에 미치는 영향을 연령에 따라 나 누어 본 연구는 없었고, 연령에 따른 리튬의 효과 차이에 관 한 연구도 부족한 실정이다. 따라서 나이에 따라 리튬이 신장 기능에 영향을 미치는 다른 요인에 대한 고려와 함께 추가 적인 연구가 필요할 것으로 보인다.

셋째, 항정신병제 사용 여부와 성별에 따른 소변 오스몰랄 농도의 변화량 차이는 유의하지 않았다. 항정신병제의 경우 저나트륨혈증을 비롯하여 혈중, 소변 오스몰랄농도에 영향 을 줄 수 있다는 연구가 있으나, ${ }^{38)}$ 리튬과 병합 사용 시 신장 에 미치는 영향을 살펴본 연구는 없었다. 본 연구에서는 항 정신병제의 경우 투약군 38명, 투약하지 않은 군이 9명으로 두 군 간의 대상자 수 차이가 커 결과에 영향을 미쳤을 가능 성이 있다. 또한 리튬 사용 후 소변 오스몰랄농도 변화량을 성별에 따라 비교한 연구는 없었으며, 이전 연구에서 일반적 으로 남성이 리튬 치료에 민감하다는 연구는 있으나, ${ }^{39)}$ 그 대 상이 1 22년 정도의 유지 치료를 시행하였던 군으로 본 연 구의 대상과는 달랐다. 다만 남녀 간의 신장기능의 차이가 다르지 않고 리튬이 성별에 따라 다른 기전으로 작용하지 않 는 것으로 미루어볼 때, 성별에 따른 리튬 사용 전후의 소변 오스몰랄농도 변화량은 차이가 나지 않을 것으로 보인다.

하지만 본 연구의 제한점으로 한 병원에 국한되어 있는 후 향적 연구라는 점이 지적될 수 있다. 또한 환자의 임상적 증 상 및 비협조 등의 이유로 인하여 lithium TDM 및 소변 오 스몰랄농도 검사가 모든 환자에게서 동일한 스케줄로 이루 어지지는 못하였다. 다음증의 지표의 경우에도 소변 오스몰 랄농도를 통해서만 요농축능을 평가하였으며, 실제 소변 오 스몰랄농도의 변화가 임상적인 수분 섭취량 및 수분 배출량 의 증가로 연결되는지에 대해서는 확인하지 못하였다. 따라 서 추후 수분 섭취량 및 배설량의 측정을 통하여 이에 대한 보완이 필요하다.

마지막으로 평균 입원 기간이 55일 내외의 단기간이기 때 문에, 리튬을 장기간 복용하였을 경우 나타나는 변화에 대해 
서는 알지 못한다. 향후 이러한 제한점들을 고려하여 추가적 인 연구를 계획하는 것을 필요할 것이다.

\section{결 론}

입원 후 처음으로 리튬 복용을 시작한 환자들을 대상으로 한 이번 연구에서, 입원 시의 소변 오스몰랄농도에 비하여 퇴원 시의 소변 오스몰랄농도는 통계학적으로 유의미하게 감소된 것으로 나타났다. 또한 14 세 미만군이 14 세 이상군에 비하여 입퇴원 시의 소변 오스몰랄농도 변화량이 많았다. 향 후 리튬이 신장에 영향을 미치는 요인을 고려하여 리튬 투 약과 다음증의 관계를 파악하는 전향적 연구가 필요하다.

중심 단어: 양극성장애 · 리튬 - 다음증 - 다뇨 · 소변 오스 몰랄농도 · 신기능.

\section{Acknowledgments}

None.

\section{Conflicts of Interest}

The authors have no financial conflicts of interest.

\section{Author Contributions}

Conceptualization: Ji-Woon Jeong, Ji-Hoon Kim. Data curation: Ji-Woon Jeong. Formal analysis: Ji-Woon Jeong. Investigation: JiWoon Jeong. Methodology: Dae-Wook Kim, Sung-Young Huh. Resources: Bum-Sung Choi, Eun-Ra Yu, Ji-Hoon Kim. Supervision: Sung-Gon Kim, Ji-Hoon Kim. Writing - original draft: Ji-Woon Jeong. Writing — review \& editing: Ji-Woon Jeong, Sung-Gon Kim, Ji-Hoon Kim.

\section{ORCID iDs}

Ji-Woon Jeong Bum-Sung Choi Dae-Wook Kim

Eun-Ra Yu Sung-Young Huh Sung-Gon Kim Ji-Hoon Kim https://orcid.org/0000-0002-9045-2494 https://orcid.org/0000-0002-1043-000X https://orcid.org/0000-0002-9623-6477 https://orcid.org/0000-0003-4149-1064 https://orcid.org/0000-0001-7617-9375 https://orcid.org/0000-0001-7566-941X https://orcid.org/0000-0001-8132-2359

\section{REFERENCES}

1) Merikangas KR, Akiskal HS, Angst J, Greenberg PE, Hirschfeld RM, Petukhova M, et al. Lifetime and 12-month prevalence of bipolar spectrum disorder in the National Comorbidity Survey replication. Arch Gen Psychiatry 2007;64:543-552.

2) Gitlin MJ, Swendsen J, Heller TL, Hammen C. Relapse and impairment in bipolar disorder. Am J Psychiatry 1995;152;1635-1640.

3) Müller-Oerlinghausen B, Berghöfer A, Bauer M. Bipolar disorder. Lancet 2002;359:241-247.

4) Martinez-Arán A, Penadés R, Vieta E, Colom F, Reinares M, Benabarre A, et al. Executive function in patients with remitted bipolar disorder and schizophrenia and its relationship with functional outcome. Psychother Psychosom 2002;71:39-46.

5) Krahn GL. WHO world report on disability: a review. Disabil Health J 2011;4:141-142.
6) Cade JF. Lithium salts in the treatment of psychotic excitement. Med J Aust 1949;2:349-352.

7) Geddes JR, Burgess S, Hawton K, Jamison K, Goodwin GM. Longterm lithium therapy for bipolar disorder: systematic review and meta-analysis of randomized controlled trials. Am J Psychiatry 2004; 161:217-222.

8) Vieta E, Azorin JM, Bauer M, Frangou S, Perugi G, Martinez G, et al. Psychiatrists' perceptions of potential reasons for non-and partial adherence to medication: results of a survey in bipolar disorder from eight European countries. J Affect Disord 2012;143:125-130.

9) Suppes T, Baldessarini RJ, Faedda GL, Tohen M. Risk of recurrence following discontinuation of lithium treatment in bipolar disorder. Arch Gen Psychiatry 1991;48:1082-1088.

10) Öhlund L, Ott M, Oja S, Bergqvist M, Lundqvist R, Sandlund M, et al. Reasons for lithium discontinuation in men and women with bipolar disorder: a retrospective cohort study. BMC psychiatry 2018; $18: 37$.

11) Gitlin M. Lithium side effects and toxicity: prevalence and management strategies. Int J Bipolar Disord 2016;4:27.

12) McKnight RF, Adida M, Budge K, Stockton S, Goodwin GM, Geddes JR. Lithium toxicity profile: a systematic review and meta-analysis. Lancet 2012;379:721-728.

13) Bendz H, Aurell M, Balldin J, Mathé AA, Sjödin I. Kidney damage in long-term lithium patients: a cross-sectional study of patients with 15 years or more on lithium. Nephrol Dial Transplant 1994;9:12501254.

14) Bendz H, Sjödin I, Aurell M. Renal function on and off lithium in patients treated with lithium for 15 years or more. A controlled, prospective lithium-withdrawal study. Nephrol Dial Transplant 1996; 11:457-460

15) van Melick EJ, Meinders AE, Hoffman TO, Egberts TC. Renal effects of long-term lithium therapy in the elderly: a cross-sectional study. Int J Geriatr Psychiatry 2008;23:685-692.

16) Gitlin M. Lithium and the kidney: an updated review. Drug Saf 1999;20:231-243.

17) Bendz H, Aurell M, Lanke J. A historical cohort study of kidney damage in long-term lithium patients: continued surveillance needed. Eur Psychiatry 2001;16:199-206.

18) Pradhan BK, Chakrabarti S, Irpati AS, Bhardwaj R. Distress due to lithium-induced polyuria: exploratory study. Psychiatry Clin Neurosci 2011;65:386-388.

19) Rej S, Segal M, Low NC, Mucsi I, Holcroft C, Shulman K, et al. The McGill geriatric lithium-induced diabetes insipidus clinical study (McGLIDICS). Can J Psychiatry 2014;59:327-334.

20) Azab AN, Shnaider A, Osher Y, Wang D, Bersudsky Y, Belmaker RH. Lithium nephrotoxicity. Int J Bipolar Disord 2015;3:13.

21) Garofeanu CG, Weir M, Rosas-Arellano MP, Henson G, Garg AX, Clark WF. Causes of reversible nephrogenic diabetes insipidus: a systematic review. Am J Kidney Dis 2005;45:626-637.

22) Grandjean EM, Aubry JM. Lithium: updated human knowledge using an evidence-based approach: part III: clinical safety. CNS Drugs 2009;23:397-418.

23) Christ-Crain M, Morgenthaler NG, Fenske W. Copeptin as a biomarker and a diagnostic tool in the evaluation of patients with polyuria-polydipsia and hyponatremia. Best Pract Res Clin Endocrinol Metab 2016;30:235-247.

24) Siegel AJ. Is urine concentration a reliable biomarker to guide vaptan usage in psychiatric patients with symptomatic hyponatremia? Psychiatry Res 2015;226:403-404.

25) Nigro N, Grossmann M, Chiang C, Inder WJ. Polyuria-polydipsia syndrome: a diagnostic challenge. Intern Med J 2018;48:244-253.

26) Markowitz GS, Radhakrishnan J, Kambham N, Valeri AM, Hines WH, D'Agati VD. Lithium nephrotoxicity: a progressive combined glomerular and tubulointerstitial nephropathy. J Am Soc Nephrol 
2000;11:1439-1448.

27) Cox M, Singer I. Lithium and water metabolism. Am J Med 1975; 59:153-157.

28) Trepiccione F, Christensen BM. Lithium-induced nephrogenic diabetes insipidus: new clinical and experimental findings. J Nephrol 2010;23 Suppl 16:S43-S48

29) Rej S, Elie D, Mucsi I, Looper KJ, Segal M. Chronic kidney disease in lithium-treated older adults: a review of epidemiology, mechanisms, and implications for the treatment of late-life mood disorders. Drugs Aging 2015;32:31-42.

30) Boton R, Gaviria M, Batlle DC. Prevalence, pathogenesis, and treatment of renal dysfunction associated with chronic lithium therapy. Am J Kidney Dis 1987;10:329-345.

31) Kearns GL, Abdel-Rahman SM, Alander SW, Blowey DL, Leeder JS, Kauffman RE. Developmental pharmacology--drug disposition, action, and therapy in infants and children. N Engl J Med 2003;349: 1157-1167.

32) Bhimma R, Purswani MU, Kala U. Kidney disease in children and adolescents with perinatal HIV-1 infection. J Int AIDS Soc 2013;16: 18596.

33) Pazhayattil GS, Shirali AC. Drug-induced impairment of renal function. Int J Nephrol Renovasc Dis 2014;7:457-468.
34) Treszl A, Tóth-Heyn P, Kocsis I, Nobilis A, Schuler Á, Tulassay T, et al. Interleukin genetic variants and the risk of renal failure in infants with infection. Pediatr Nephrol 2002;17:713-717.

35) Pettit JW, Paukert AL, Joiner TE Jr, Rudd MD. Pilot sample of very early onset bipolar disorder in a military population moderates the association of negative life events and non-fatal suicide attempt. Bipolar Disord 2006;8:475-484

36) Propper L, Ortiz A, Slaney C, Garnham J, Ruzickova M, Calkin CV, et al. Early-onset and very-early-onset bipolar disorder: distinct or similar clinical conditions? Bipolar Disord 2015;17:814-820.

37) Perlis RH, Miyahara S, Marangell LB, Wisniewski SR, Ostacher M, DelBello MP, et al. Long-term implications of early onset in bipolar disorder: data from the first 1000 participants in the systematic treatment enhancement program for bipolar disorder (STEP-BD). Biol Psychiatry 2004;55:875-881.

38) Atsariyasing W, Goldman MB. A systematic review of the ability of urine concentration to distinguish antipsychotic-from psychosis-induced hyponatremia. Psychiatry Res 2014;217:129-133.

39) Rybakowski JK, Abramowicz M, Drogowska J, Chłopocka-Woźniak M, Michalak M, Czekalski S. Screening for the markers of kidney damage in men and women on long-term lithium treatment. Med Sci Monit 2012;18:CR656-CR660. 